\title{
Changes in daily extreme precipitation events in South China from 1961 to 2011
}

\author{
REN Zhengguo, "ZHANG Mingjun, WANG Shengjie, QIANG Fang, ZHU Xiaofan, \\ DONG Lei
}

College of Geography and Environmental Science, Northwest Normal University, Lanzhou 730070, China

\begin{abstract}
Based on the daily precipitation from a $0.5^{\circ} \times 0.5^{\circ}$ gridded dataset and meteorological stations during 1961-2011 released by National Meteorological Information Center, the reliability of this gridded precipitation dataset in South China was evaluated. Five precipitation indices recommended by the World Meteorological Organization (WMO) were selected to investigate the changes in precipitation extremes of South China. The results indicated that the bias between gridded data interpolated to given stations and the corresponding observed data is limited, and the proportion of the number of stations with bias between $-10 \%$ and 0 is $50.64 \%$. The correlation coefficients between gridded data and observed data are generally above 0.80 in most parts. The average of precipitation indices shows a significant spatial difference with drier northwest section and wetter southeast section. The trend magnitudes of the maximum 5-day precipitation (RX5day), very wet day precipitation (R95), very heavy precipitation days (R20mm) and simple daily intensity index (SDII) are $0.17 \mathrm{~mm} \cdot \mathrm{a}^{-1}$, $1.14 \mathrm{~mm} \cdot \mathrm{a}^{-1}, 0.02 \mathrm{~d} \cdot \mathrm{a}^{-1}$ and $0.01 \mathrm{~mm} \cdot \mathrm{d}^{-1} \cdot \mathrm{a}^{-1}$, respectively, while consecutive wet days (CWD) decrease by $-0.05 \mathrm{~d} \cdot \mathrm{a}^{-1}$ during $1961-2011$. There is spatial disparity in trend magnitudes of precipitation indices, and approximate $60.85 \%, 75.32 \%$ and $75.74 \%$ of the grid boxes show increasing trends for RX5day, SDII and R95, respectively. There are high correlations between precipitation indices and total precipitation, which is statistically significant at the 0.01 level.
\end{abstract}

Keywords: precipitation extremes; gridded data; South China

\section{Introduction}

Under global warming during the last decades, the precipitation events generally present a trend of extremelization, and the frequent natural disasters caused by precipitation extremes (such as flash floods and snow storms) have a dramatic impact on social and economic development (Easterling et al., 2000; Changnon et al., 2000). Recent changes in extreme pre-

Received: 2014-05-20 Accepted: 2014-06-15

Foundation: National Basic Research Program of China (973Program), No.2013CBA01801; National Natural Science Foundation of China, No.41161012

Author: Ren Zhengguo (1989-), MS Candidate, specialized in global change and sustainable development.

E-mail: Georen@126.com

*Corresponding author: Zhang Mingjun, Professor, E-mail: mjzhang2004@163.com 
cipitation events in different regions have been evaluated by long-term observational data of precipitation (Fu et al., 2013; Re et al., 2009; Hu et al., 2012; Wang et al., 2013b). However, the meteorological stations are still not distributed properly, resulting in an uncertain representativeness of observed precipitation, especially in remote areas. This problem can be solved based on the gridded reanalysis data, but it should not be ignored that the spatial resolution of existing gridded data is generally limited and the internal uncertainty still needs further evaluation. A research in Australia (King et al., 2013) indicates that the gridded dataset can be used to investigate extreme heavy precipitation, though the intensity of extreme heavy precipitation events and their contribution to annual precipitation tend to be underestimated and the frequency and intensity of light precipitation has been overestimated. An earlier study on European extreme precipitation, using 4 sets of reanalysis data (Zolina et al., 2004), demonstrates that the estimation capacity of the extreme precipitation is quite different for each gridded dataset. Similar conclusions can be found in other previous researches (e.g., Herrera et al., 2012; Hofstra et al., 2010; Haylock et al., 2008). Generally, interpolation method and observation station distribution have a great impact on data accuracy, and the gridded data are also related to the reliability and homogeneity of assimilated data series. In addition, some researchers have also implemented comparison work of near-surface precipitation extremes in model simulations, reanalysis data, and observations (Kharin et al., 2005; Caeser et al., 2012).

South China, which lies in the east of the Qinghai-Tibet Plateau and the south of the Qinling Mountains-Huaihe River line, is a monsoon region with abundant precipitation and a large population. The extreme precipitation events of this region may have a great influence. A nation-wide study in China (Wang and Qian, 2009) indicates that the frequency of extreme precipitation events is higher in the region south of $35^{\circ} \mathrm{N}$, than that in other parts of China, especially in the middle and lower reaches of the Changjiang (Yangtze) River and the southeastern part of the Tibetan Plateau. Although the extreme precipitation events in South China has been involved in many case studies (Wang et al., 2014; Gemmer et al., 2011; Li et al., 2011), only observational data in meteorological stations has been used and the gridded precipitation data are less involved for extreme precipitation research in South China.

So far, several global gridded precipitation datasets with high resolution (grid boxes less than $0.5^{\circ} \times 0.5^{\circ}$ ) have been released, such as GPCP (Global Precipitation Climatology Project; $\mathrm{Li}$ and Fu, 2005; Zi et al., 2007), CRU (Climatic Research Unit; Wen et al., 2006), APHRODITE (Asian Precipitation-Highly Resolved Observational Data Integration Towards Evaluation of Water Resources; Han et al., 2012), etc. Actually, there are only a few assimilated stations in China involved in these global datasets, so their applicability needs to be systematically evaluated before being used in climate research. In 2012, the National Meteorological Information Center (NMIC) and China Meteorological Administration (CMA) released a gridded daily precipitation dataset (China Ground Precipitation $0.5^{\circ} \times 0.5^{\circ}$ Grid Dataset, V 2.0). Previous investigation shows that this dataset can effectively resolve the problem about underestimated precipitation at mountainous area in arid region (Wang et al., 2013c). However, the applicability of this gridded data in South China with wet climate pattern still needs to be further evaluated. In this study, several precipitation indices recommended by the World Meteorological Organization (WMO) were selected to investigate the precipitation extremes in South China by using gridded and observed data. 


\section{Data and methods}

\subsection{Data source}

In this study, the gridded data (China Ground Precipitation $0.5^{\circ} \times 0.5^{\circ}$ Grid Dataset, V 2.0) was provided by the National Meteorological Information Center (NMIC) and China Meteorological Administration (CMA). The gridded dataset is based on the observed daily precipitation at 2474 meteorological stations and the GTOPO30 (Global 30 arc-second elevation) DEM data, which eliminates the influence of complex elevation. Details of this precipitation dataset are described in NMIC (2012).

South China in this study refers to the southern part of China's eastern monsoon region, mainly to the south of the Qinling Mountains-Huaihe River line and the east of Qinghai-Tibet Plateau, where the coastline length accounted for more than two-thirds in China (Zhao, 1983). According to the boundary of South China, 876 grid boxes were selected from the dataset, excluding Taiwan Island and South China Sea Islands (Figure 1). In order to verify the precipitation derived from the gridded precipitation data, 235 in-situ meteorological stations in South China were also selected. The daily precipitation data during the period of 1961-2011 was also collected from NMIC. Strict quality controls, including checks for high-low extremes and time consistency, are applied and detected errors are corrected by NMIC.

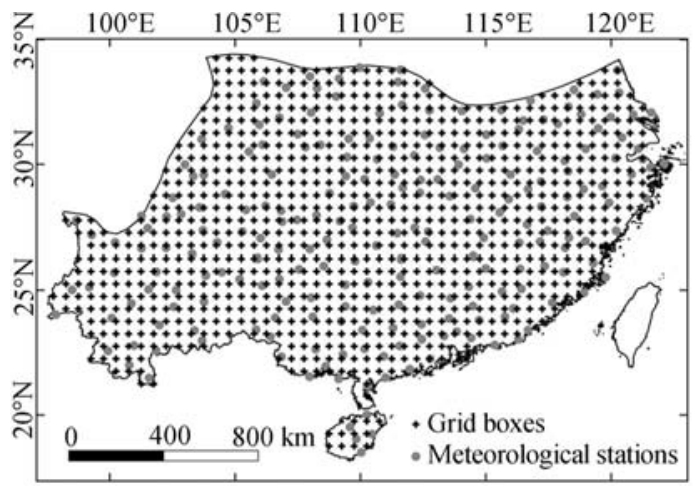

Figure 1 Map showing the distribution of observation stations and grid boxes in South China

\subsection{Methods}

In this study, a total of five precipitation indices were selected from the core indices list recommended by the ETCCDI (Expert Term on Climate Change Detection and Indices) (Table 1), which is a joint team of the World Meteorological Organization's Commission for Climatology $(\mathrm{CCl})$, the World Climate Research Programmer's Climate Variability and Predictability (CLIVAR) and the Joint Technical Commission for Oceanography and Marine Meteorology (JCOMM). These selected indices are widely applied to investigate the changes in daily precipitation extremes (Skansi et al., 2013; Rao et al., 2014; Donat et al., 2014), which can reflect the changes in precipitation extremes.

In order to compare the differences between observed and gridded data, the nearest 4 stations to the given meteorological station are weighted to calculate an average. Inverse distance weighted (IDW) is used in interpolation and the formula is given as follows: 


$$
P=\frac{\sum_{i=1}^{n} \frac{P_{i}}{d_{i}}}{\sum_{i=1}^{n} \frac{1}{d_{i}}}
$$

Table 1 Definition of precipitation indices in this study

\begin{tabular}{cllc}
\hline Index & \multicolumn{1}{c}{ Descriptive name } & \multicolumn{1}{c}{ Definition } & Units \\
\hline RX5day & Maximum 5-day precipitation & Annual maximum consecutive 5-day precipitation & $\mathrm{mm}$ \\
\multirow{2}{*}{ R95 } & Very wet day precipitation & $\begin{array}{l}\text { Annual total precipitation when RR>95th percentile of } \\
\text { 1961-2011 daily rainfall }\end{array}$ & $\mathrm{mm}$ \\
SDII & Simple daily intensity index & Average precipitation on wet days & $\mathrm{mm} \cdot \mathrm{d}^{-1}$ \\
CWD & Consecutive wet days & Maximum number of consecutive wet days & $\mathrm{d}$ \\
R20mm & Very heavy precipitation days & Annual count of days when RR $\geqslant 20 \mathrm{~mm}$ & $\mathrm{~d}$ \\
\hline
\end{tabular}

where $P_{i}$ is the observed precipitation of the nearest 4 grid boxes, respectively; $d_{i}$ is the distance between the central station and the surrounding 4 grids. If there are less than 2 grid boxes around the central location (e.g. in coastal areas), the nearest 12 stations are considered in spatial interpolation.

Bias $(B)$ is used to describe the difference between a station and interpolated gridded data, and the formula is as follows:

$$
B=100 \times \frac{\overline{P_{\text {grid }}}-\overline{P_{\text {obs }}}}{\overline{P_{\text {obs }}}},
$$

where $\overline{P_{\text {grid }}}$ and $\overline{P_{\text {obs }}}$ are the mean value of interpolated grids and observed stations, respectively.

The nonparametric Sen's method (Sen, 1968) is employed to calculate the trends of each precipitation index and the statistical significance of linear trend is examined using a Mann-Kendall test. The spatial distribution maps of trend magnitudes of precipitation indices are drawn using ArcGIS9.3. SPSS19 is employed to calculate principal component analysis (PCA) and correlation analysis.

\section{Results}

\subsection{Comparison between gridded and observed data}

According to the bias of interpolated precipitation shown in Figure 2a, bias at most (85.26\%) stations mainly concentrates between $-20 \%$ and $-10 \%$. The proportion of stations with biases ranging between $-10 \%$ and 0 is $50.64 \%$. The linear relationship of annual mean precipitation between observations and interpolated grids (Figure 2b) indicates a good correlation $(R=0.8528)$, which is statistically significant at the 0.0001 level. It is worth noting that the annual precipitation may be underestimated for these wetter stations (especially the station with annual precipitation larger than $2000 \mathrm{~mm}$ ), which leads to a slight slope of linear regression line. The standard deviations between daily observation stations and interpolated grids (Figure 2c) also shows a high correlation coefficient $(R=0.83, P<0.0001)$, though the 
deviation of each station is mainly on the bottom right of the diagonal line $(y=x)$. Generally, the interpolated grids can well reflect the precipitation in South China.

Figure 3a shows the spatial distribution of biases of interpolated gridded precipitation, and generally the biases are evenly distributed except southwestern part with complex terrain (most observed stations are located at lower altitude). The correlation coefficients are generally above 0.80 in most parts (Figure 3b), where some parts in southwestern and coastal area is relatively low (below 0.75). However, the relatively large biases (with lower correlation coefficients) found at some individual stations cannot hinder the main spatial pattern of good correlation in most parts of South China.
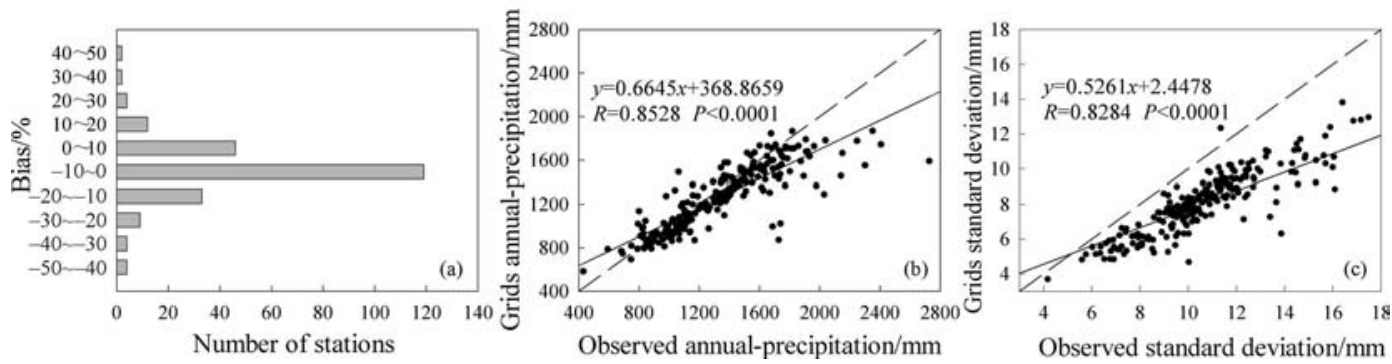

Figure 2 Number distribution of interpolated grids for different bias ranges (a), and relationship of annual average precipitation (b) and standard deviation on daily basis (c) between observation stations and interpolated grids in South China during 1961-2011

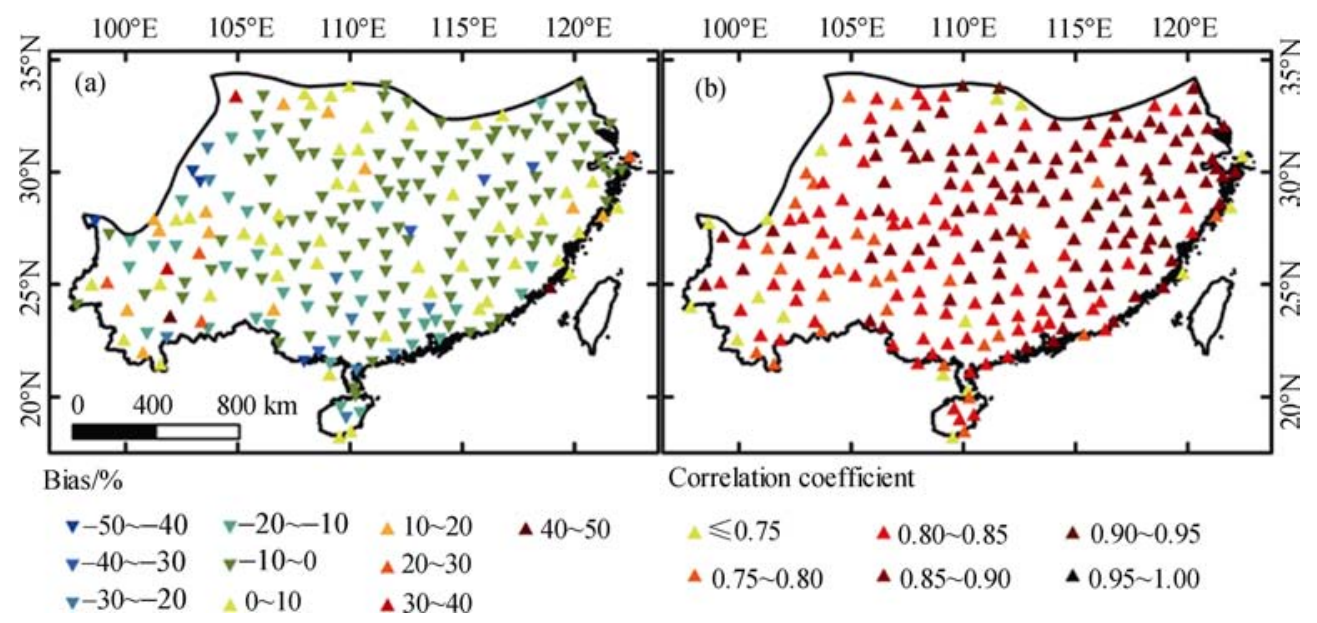

Figure 3 Spatial distribution of biases of interpolated gridded precipitation (a) and correlation coefficient of annual precipitation between interpolated grids and observation stations (b) in South China during 1961-2011

\subsection{Spatial distribution of precipitation indices}

During the study period, the mean values of precipitation indices generally display a decreasing trend from east to west and south to north (Figure 4), i.e., drier northwest and wetter southeast. For the whole region, mean value of maximum 5-day precipitation (RX5day) is mainly between 100 and $150 \mathrm{~mm}$, and the part with $200 \mathrm{~mm}$ above is in Hainan Island and southeastern coastal areas while some western part is below $100 \mathrm{~mm}$. The absolute value of 
very wet day precipitation (R95) is generally higher than that of RX5day, and the part with more than $350 \mathrm{~mm}$ can be found in Hainan Island and southeastern coastal areas. By contrast, the mean value of consecutive wet days (CWD) shows significant zonal distribution with lower in north and higher in south. The mean value of very heavy precipitation days (R20mm) is mostly more than 20 days in southeastern coastal areas while fewer than 10 days in some western parts. The mean value of simple daily intensity index (SDII) is above $12 \mathrm{~mm} \cdot \mathrm{d}^{-1}$ for fewer grids in coastal areas, while it generally shows below $8 \mathrm{~mm} \cdot \mathrm{d}^{-1}$ in western areas.

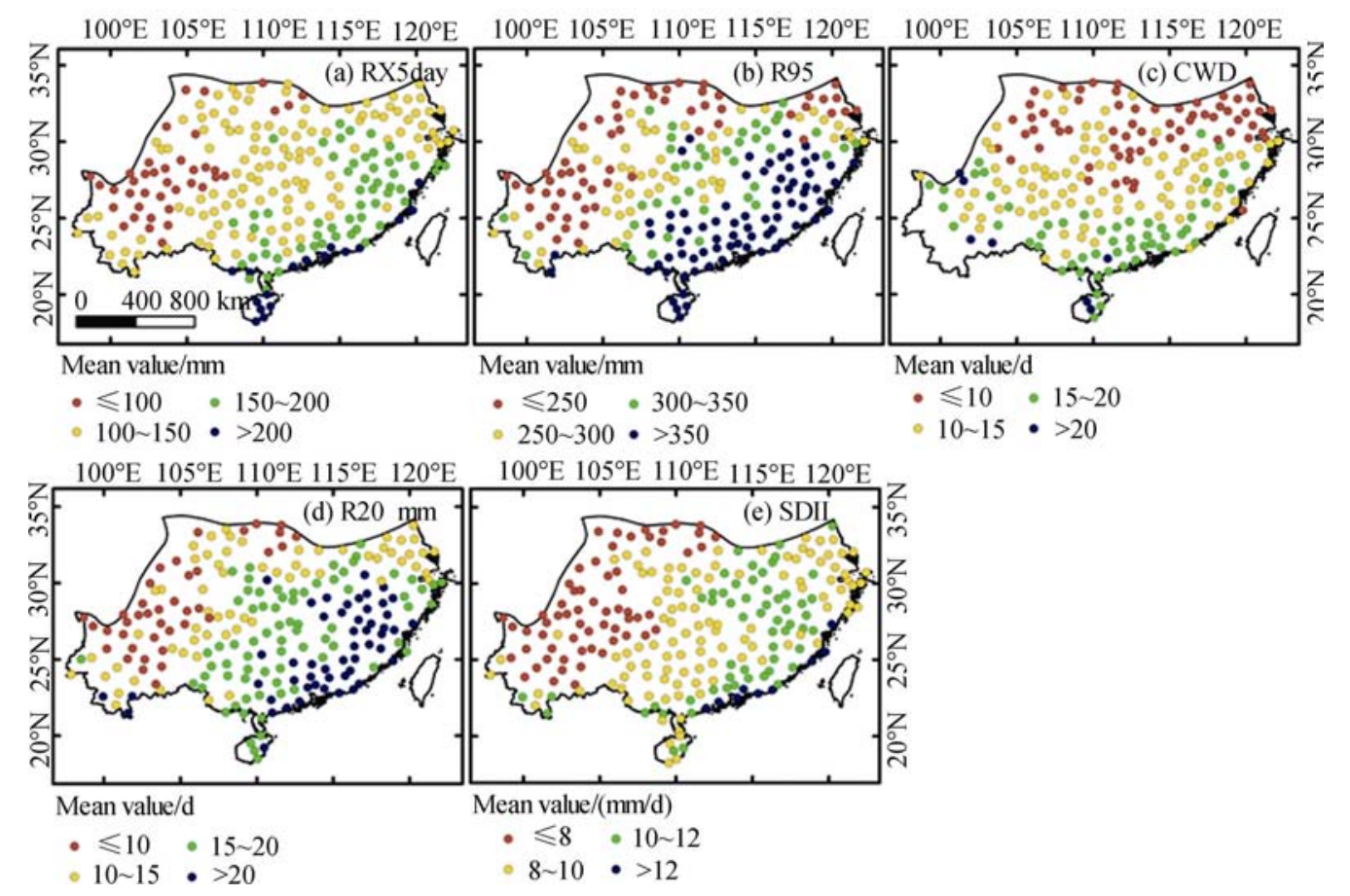

Figure 4 Spatial distribution of annual mean precipitation indices in South China during 1961-2011

\subsection{Temporal variation of precipitation indices}

Figure 5 shows the temporal variation of precipitation indices in South China during 1961-2011. Most indices show increasing trends except CWD. RX5day, R95, R20mm and SDII have increased by $0.17 \mathrm{~mm} \cdot \mathrm{a}^{-1}, 1.14 \mathrm{~mm} \cdot \mathrm{a}^{-1}, 0.02 \mathrm{~d} \cdot \mathrm{a}^{-1}$ and $0.01 \mathrm{~mm} \cdot \mathrm{d}^{-1} \cdot \mathrm{a}^{-1}$, respectively, among which the change of SDII is statistically significant at the 0.01 level $(P=0.0021)$. CWD has decreased by $-0.05 \mathrm{~d}^{-1} \cdot \mathrm{a}^{-1}$. According to the moving average curve, RX5day shows several higher periods between the 1960s and 1990s (Figure 5a), and the fluctuation of R95 is similar to RX5day (Figure 5b). CWD displays a decreasing trend with the highest value in the 1990s (Figure 5c), and among which R20mm (Figure 5d) and SDII (Figure 5e) also display high value during the same period.

\subsection{Spatial variation of precipitation indices}

During 1961-2011, there is a difference of spatial variation existing in precipitation indices. For RX5day (Figure 6a), increasing trend shows in eastern part, and decreasing trend can 

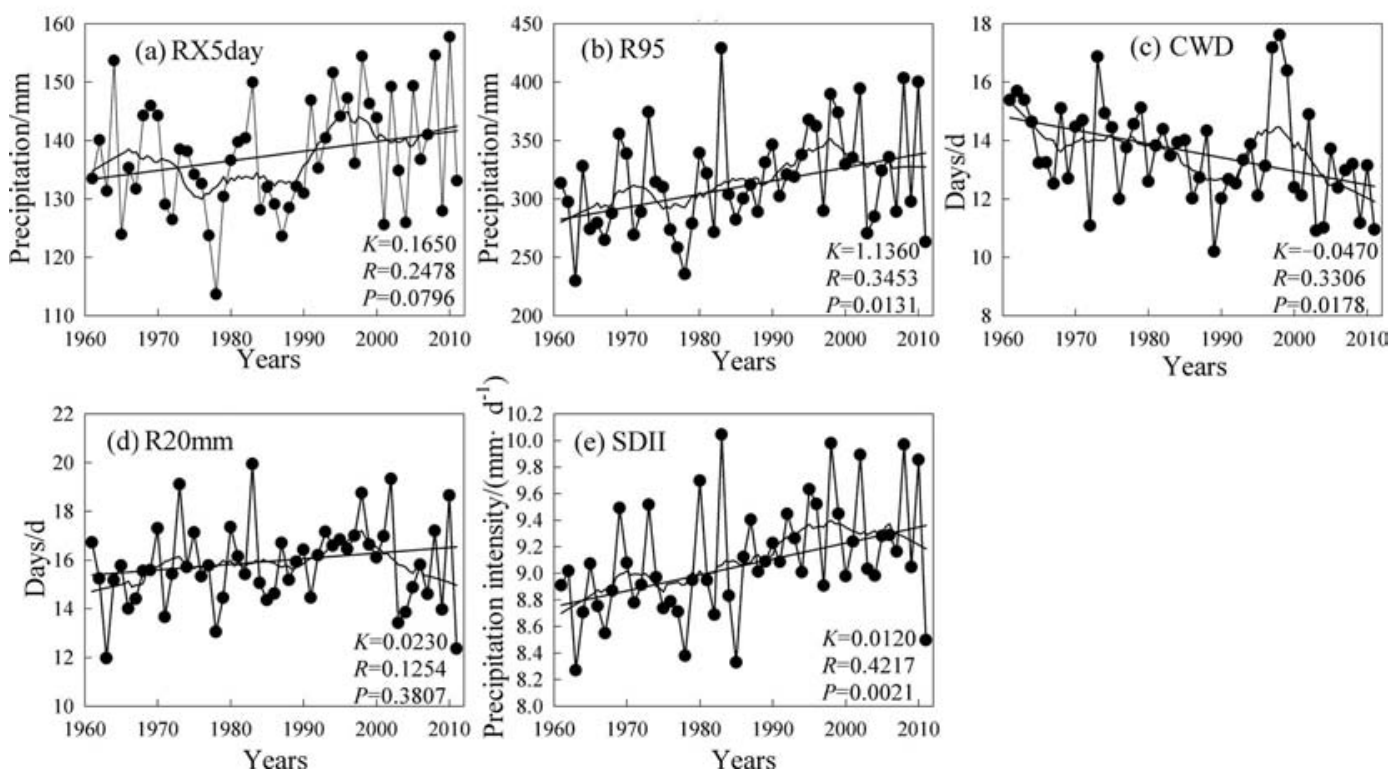

Figure 5 Interannual variation of precipitation indices in South China during 1961-2011
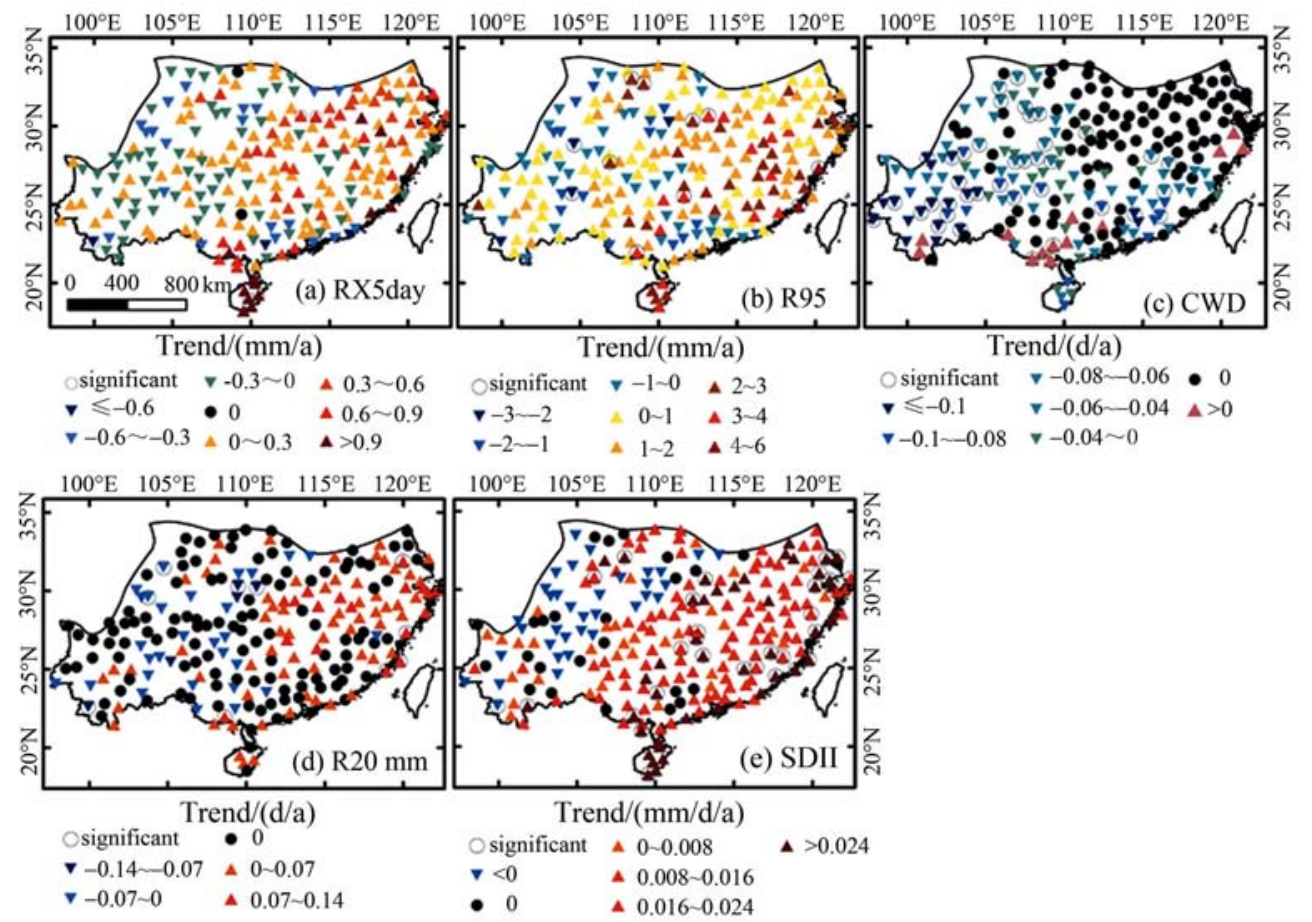

Figure 6 Spatial distribution of trend magnitude of precipitation indices in South China during 1961-2011

be found in western part. In Hainan Island, the increasing trend is up to $0.09 \mathrm{~mm} \mathrm{a}^{-1}$. R95 at about $75.74 \%$ grids presents increasing trend (Figure $6 \mathrm{~b}$ ), in which precipitation shows lar- 
ger variation in coastal area, but smaller in inland area. For CWD, decreasing trend is majorly presented (Figure 6c) by accounting for $47.23 \%$ of grid boxes. There are $45.96 \%$ grid boxes without changing trend ,which are mainly distributed in the middle and lower reaches of the Changjiang (Yangtze) River, and only 6.81\% grid boxes display an increasing trend since 1961 in the whole region. As shown in Figure 6d, R20mm shows an increasing trend in the east with larger magnitudes, while mainly decreasing trend appears in the west with smaller amplitude. About $48.51 \%$ of grid boxes in the whole region show no changing trend. The spatial distributions of SDII (Figure 6e) show the trend similar to R20mm, but the stations without changing trend are less than those of R20mm.

\subsection{Coherence of precipitation indices}

In previous studies, annual total precipitation may not have good correlation with drought events (Gong and Han, 2004), but good relationship with RX5day and SDII (You et al., 2011; Wang et al., 2013a). In order to examine the relationship between precipitation indices and annual total precipitation, the results of principal component and correlation analysis are shown in Tables 2 and 3, respectively. The principal component analysis indicates that all the indices are highly loading in the first factor, holding an explained variance of $65.21 \%$, except CWD (in the second highly loading, holding $18.05 \%$ variance). So the coherence of total precipitation and precipitation indices can be clearly found.

Table 2 Factor loadings and explained variances in precipitation indices in South China during 1961-2011

\begin{tabular}{cccccccc}
\hline Factor & Annual precipitation & RX5day & R95 & CWD & R20mm & SDII & Variance (\%) \\
\hline 1 & 0.875 & 0.737 & 0.942 & 0.330 & 0.940 & 0.851 & 65.209 \\
2 & 0.248 & -0.020 & -0.241 & 0.907 & 0.046 & -0.371 & 18.046 \\
\hline
\end{tabular}

Table 3 shows that there are good correlations between each precipitation index and total precipitation, which are statistically significant at the 0.01 level, in which R95 and R20mm show the best correlation with the total precipitation and the correlation coefficient above 0.70 . The correlation coefficient between precipitation and others are generally above 0.44 , except CWD. Therefore, the increase or decrease of precipitation indices selected in this study can be reflected in the increase or decrease of total precipitation. In addition, there is good correlation among each precipitation index $(P<0.0001)$.

Table 3 Correlation coefficients of precipitation indices in South China during 1961-2011

\begin{tabular}{|c|c|c|c|c|c|c|}
\hline & Annual precipitation & RX5day & R95 & CWD & $\mathrm{R} 20 \mathrm{~mm}$ & SDII \\
\hline Annual precipitation & 1 & & & & & \\
\hline RX5day & $0.492^{* *}$ & 1 & & & & \\
\hline R95 & $0.731^{* *}$ & $0.709^{* *}$ & 1 & & & \\
\hline CWD & $0.412^{* *}$ & 0.261 & 0.115 & 1 & & \\
\hline $\mathrm{R} 20 \mathrm{~mm}$ & $0.937^{* *}$ & $0.508^{* *}$ & $0.839^{* *}$ & $0.299^{*}$ & 1 & \\
\hline SDII & $0.565^{* *}$ & $0.570^{* *}$ & $0.887^{* *}$ & 0.021 & $0.769^{* *}$ & 1 \\
\hline
\end{tabular}

Note: * Statistical significance at the 0.05 level. ** Statistical significance at the 0.05 level. 


\section{Discussion}

Many researches (King et al., 2013; Zolina et al., 2004; Herrera et al., 2012; Hofstra et al., 2010; Haylock et al., 2008) used high-resolution gridded precipitation data to examine extreme precipitation events, but the precondition is clear acquaintance to the data accuracy. In this study, the gridded precipitation dataset of $0.5^{\circ} \times 0.5^{\circ}$ resolution, with the most assimilated ground stations than ever before in South China, is selected and evaluated in the study of regional precipitation extremes. Because of the great influence of underlying surface on precipitation, and complex distribution of precipitation existing widely, in some mountainous areas, the existing meteorological stations are usually concentrated in low-altitude intermontane basin or valley, which may cause the difference between observed and actual regional precipitation amount. From the bias and standard deviation of gridded precipitation calculated in this study, in general, the gridded dataset released by the NMIC well correlates with observed data, and the bias at daily level is generally in $\pm 10 \%$. In other words, this gridded dataset have good creditability in this study.

The trends in long-term precipitation show more complex spatial and temporal pattern, compared with the commonly increasing trend of air temperature. At the national scale in China, being limited to the uneven distribution of meteorological stations, the different precipitation trend (increase or decrease) can be calculated by different scholars using the meteorological station data and interpolation approach (Wang et al., 2012; You et al., 2009). In this study, based on the gridded data, the increasing trend is shown in the selected precipitation indices, which is consistent with the early researches (Wang et al., 2014; Li et al., 2011; You et al., 2011). Besides, it is worth noting that the different trend of drying and/or wetting is exhibited between eastern and western parts, where far-reaching significance for response of regional drought and flood is given (Zhang et al., 2013; Chen et al., 2011).

\section{Conclusions}

Based on the daily precipitation from a $0.5^{\circ} \times 0.5^{\circ}$ gridded dataset and meteorological stations during 1961-2011 released by the NMIC, five precipitation indices were selected, and the reliability of this gridded precipitation dataset in South China was evaluated. The results are given as follows:

(1) According to the bias of interpolated precipitation, bias at most (85.26\%) stations mainly concentrates between $-20 \%$ and $-10 \%$, the correlation coefficients between gridded data and observed data are generally above 0.80 in most parts. The dataset can be used to investigate the precipitation extremes in South China.

(2) For the whole region, maximum 5-day precipitation (RX5day), very wet day precipitation (R95), very heavy precipitation days (R20mm) and simple daily intensity index (SDII) show increasing trend by $0.17 \mathrm{~mm} \cdot \mathrm{a}^{-1}, 1.14 \mathrm{~mm} \cdot \mathrm{a}^{-1}, 0.02 \mathrm{~d} \cdot \mathrm{a}^{-1}$ and $0.01 \mathrm{~mm} \cdot \mathrm{d}^{-1} \cdot \mathrm{a}^{-1}$, respectively, while decreasing trend appears in consecutive wet days (CWD). There is spatial disparity for each index tendency, where approximately $60.85 \%, 75.32 \%$ and $75.74 \%$ of the grid boxes show increasing trends for RX5day, SDII and R95, respectively.

(3) Principal component analysis of the extreme precipitation indices are divided into two parts with a total contribution rate of 83.3\%. With the exception of CWD, R95, RX5day, SDII, R20mm are well correlated with each other, which are statistically significant at the 
0.01 level.

\section{References}

Caesar J, Lowe J A, 2012. Comparing the impacts of mitigation versus non-intervention scenarios on future temperature and precipitation extremes in the HadGEM2 climate model. Journal of Geophysical Research: Atmospheres, 117, D15109, doi: 10.1029/2012JD017762.

Changnon S A, Roger A, Pielke J et al., 2000. Human factors explain the increased losses from weather and climate extremes. Bulletin of the American Meteorological Society, 81(3): 437-442.

Chen Ying, Yin Yixing, Chen Xingwei, 2011. Change of flood disasters in China since the 1880s and some possible causes. Journal of Natural Resources, 26(12): 2110-2120. (in Chinese)

Donat M G, Peterson T C, Brunet M et al., 2014. Changes in extreme temperature and precipitation in the Arab region: Long-term trends and variability related to ENSO and NAO. International Journal of Climatology, 34(3): 581-592.

Easterling D R, Events J L, Groismman P Ya et al., 2000. Observed variability and trends in extreme climate events: A brief review. Bulletin of the American Meteorological Society, 81(3): 417-425.

Fu Guobin, Yu Jingjie, Yu Xiubo et al., 2013. Temporal variation of extreme rainfall events in China, 1961-2009. Journal of Hydrology, 487: 48-59.

Gao Huixuan, 2005. Application of Multivariate Statistical Analysis. Beijing: Peking University Press, 1-213. (in Chinese)

Gemmer M, Fischer T, Jiang Tong et al., 2011. Trends in precipitation extremes in the Zhujiang River Basin, South China. Journal of Climate, 24(3): 750-761.

Gong Daoyi, Han Hui, 2004. Extreme climate events in northern China over the last 50 years. Acta Geographica Sinica, 59(2): 230-238. (in Chinese)

Han Zhenyu, Zhou Tianjun, 2012. Assessing the quality of APHRODITE high-resolution daily precipitation dataset over contiguous China. Chinese Journal of Atmospheric Sciences, 36(2): 361-373. (in Chinese)

Haylock M R., Hofstra N, Klein Tank A M G et al., 2008. A European daily high-resolution gridded data set of surface temperature and precipitation for 1950-2006. Journal of Geophysical Research, 113, D20119, doi: 10.1029/2008JD010201.

Herrera S, Gutiérrez J M, Ancell R et al., 2012. Development and analysis of a 50-year high-resolution daily gridded precipitation dataset over Spain (Spain02). Journal of Climatology, 32(1): 74-85.

Hofstra N, New M, McSweeney C, 2010. The influence of interpolation and station network density on the distributions and trends of climate variables in gridded daily data. Climate Dynamics, 35(5): 841-858.

Hu Yurong, Maskey S, Uhlenbrook S, 2012. Trends in temperature and rainfall extremes in the Yollow River source, China. Climatic Change, 110: 403-329.

Kharin V V, Francis W Z, Zhang Xuebin et al., 2005. Intercomparison of near-surface temperature and precipitation extremes in AMIP-2 simulations, reanalyses, and observations. Journal of Climate, 18: 5201-5223.

King A D, Alexandera L V, Donata M G, 2013. The efficacy of using gridded data to examine extreme rainfall characteristics: A case study for Australia. International Journal of Climatology, 33(10): 2376-2387.

Li Rui, Fu Yunfei, 2005. A comparison study of the tropical monthly precipitation estimated by GPCP Version 2 Datasets and TRMM PR observations. Acta Meteorologica Sinica, 63(2): 146-160. (in Chinese)

Li Zongxing, He Yuanqing, Wang Puyu et al., 2011. Changes of daily climate extremes in southwestern China during 1961-2008. Global and Planetary Change, 80/81: 255-272.

National Meteorological Information Center, 2012. Assessment Report of China's Ground Precipitation $0.5^{\circ} \times 0.5^{\circ}$ Gridded Dataset (V2.0). Beijing: National Meteorological Information Center. (in Chinese)

Rao K K, Patwardhan S K, Kulkarni A et al., 2014. Projected changes in mean and extreme precipitation indices over India using PRECIS. Global and Planetary Change, 113: 77-90.

Re M, Barros V R, 2009. Extreme rainfalls in SE South America. Climatic Change, 96: 119-136.

Sen P K, 1968. Estimates of the regression coefficient based on Kendall's tau. Journal of American Statistical 
Association, 39: 1379-1389.

Skansi M M, Brunet M, Sigró J et al., 2013. Warming and wetting signals emerging from analysis of changes in climate extreme indices over South America. Global and Planetary Change, 100: 295-307.

Wang Baolong, Zhang Mingjun, Wei Junlin et al., 2013a. Changes in extreme precipitation over Northeast China, 1960-2009. Quaternary International, 298(17): 177-186.

Wang Chenghai, Li Jian, Li Xiaolan et al., 2012. Analysis on quasi-periodic characteristics of precipitation in recent 50 years and trend in next 20 years in China. Arid Zone Research, 29(1): 1-10. (in Chinese)

Wang Huaijun, Chen Yaning, Chen Zhongsheng, 2013b. Spatial distribution and temporal trends of mean precipitation and extremes in the arid region, northwest of China, during 1960-2010. Hydrological Processes, 27(12): 1807-1818.

Wang Jing'ai, 2006. China Geography Course. Beijing: Higher Education Press, 479-518. (in Chinese)

Wang Qiong, Zhang Mingjun, Wang Shengjie et al., 2014. Changes in temperature extremes in the Yangtze River Basin, 1962-2011. Journal of Geographical Sciences, 24(1): 59-75.

Wang Shengjie, Zhang Mingjun, Sun Meiping et al., 2013c. Changes in precipitation extremes in alpine areas of the Chinese Tianshan Mountains, central Asia, 1961-2011. Quaternary International, 311: 97-107.

Wang Zhifu, Qian Yongfu, 2009. Frequency and intensity of extreme precipitation events in China. Advances in Water Science, 20(1): 1-9. (in Chinese)

Wen Xinyu, Wang Shaowu, Zhu Jinhong et al., 2006. An overview of China climate change over the 20th century using UK UEA/CRU high resolution grid data. Chinese Journal of Atmospheric Sciences, 30(5): 894-904. (in Chinese)

You Qinglong, Kang Shichang, Aguilar E et al., 2011. Changes in daily climate extremes in China and its connection to the large scale atmospheric circulation during 1961-2003. Climate Dynamics, 36: 2399-2417.

You Qinglong, Kang Shichang, Yan Yuping et al., 2009. Trends in daily temperature and precipitation extremes over the Yarlung Zangbo River Basin during 1961-2005. Acta Geographica Sinica, 64(5): 592-600. (in Chinese)

Zhang Mingjun, He Jinyun, Wang Baolong et al., 2013. Extreme drought changes in Southwest China from 1960 to 2009. Journal of Geographical Sciences, 23(1): 3-16.

Zhang Yaoting, 2003. Lecture Notes of Multiple Statistical Analysis. Beijing: China Statistics Press, 1-144. (in Chinese)

Zhao Songqiao, 1983. A new scheme for comprehensive physical regionalization in China. Acta Geographica Sinica, 38(1): 1-10. (in Chinese)

Zi Yong, Xu Yinlong, Fu Yunfei, 2007. Climatological comparison studies between GPCP and rain gauges precipitations in China. Acta Meteorologica Sinica, 65(1): 63-74. (in Chinese)

Zolina O, Kapala A, Simmer C et al., 2004. Analysis of extreme precipitation over Europe from different reanalyses: A comparative assessment. Global and Planetary Change, 44: 129-161. 